\title{
Epirubicin directly promotes hepatitis B virus (HBV) replication in stable HBV-expressing cell lines: A novel mechanism of HBV reactivation following anticancer chemotherapy
}

\author{
LEI XU ${ }^{1,2}$, ZENG TU $^{1,2}$, GE XU $^{1}$, YUWEI WANG ${ }^{1}$, WANLONG PAN ${ }^{3}$, XINGXING ZHAN $^{4}$, \\ QIANG LUO $^{1}$, YUAN HUANG $^{1}$, JUAN CHEN $^{1}$ and AILONG HUANG ${ }^{1}$ \\ ${ }^{1}$ Laboratory of Molecular Biology on Infectious Diseases, Ministry of Education, Second Affiliated Hospital, \\ Chongqing Medical University, Chongqing 400016; ${ }^{2}$ Department of Microbiology, \\ Chongqing Medical University, Chongqing 400016; ${ }^{3}$ Department of Microbiology and Immunology, \\ North Sichuan Medical College, Nanchong, Sichuan 637000; ${ }^{4}$ Department of Pediatrics, \\ Chongqing Medical University, Chongqing 400016, P.R. China
}

Received September 9, 2013; Accepted February 6, 2014

DOI: $10.3892 / \mathrm{mmr} .2014 .1973$

\begin{abstract}
Chronic hepatitis B virus (HBV) infection is a worldwide problem and HBV reactivation following anticancer chemotherapy has become an emerging clinical challenge. However, the mechanisms of HBV reactivation following chemotherapy remain unclear. Epirubicin is an anthracycline drug used in chemotherapy to treat numerous types of malignancy, including breast cancer, acute leukemia, malignant lymphoma, lung cancer, ovarian cancer and stomach cancer. Epirubicin acts by intercalating DNA strands and inhibiting DNA and RNA synthesis. In this study, it was demonstrated that epirubicin directly upregulated the levels of in vitro HBV replication in a concentration-dependent manner. Exposure to epirubicin for $24 \mathrm{~h}$ induced $>11-$ and 6-fold increases in the levels of intracellular and secreted HBV DNA, respectively. In concordance with the elevated levels of HBV DNA, the expression levels of HBV pregenomic RNA, intracellular HBV surface and HBV core antigens, and secreted HBV e antigen were significantly increased by treatment with $0.5 \mu \mathrm{M}$ epirubicin. Notably, epirubicin promoted cellular excretion of HBV nucleocapsids, which are closely associated with the pathological effects of HBV, including acute liver failure. In conclusion, epirubicin exhibited a direct stimulatory effect on HBV replication and this may be
\end{abstract}

Correspondence to: Professor AiLong Huang or Miss Juan Chen, Laboratory of Molecular Biology on Infectious Diseases, Ministry of Education, Second Affiliated Hospital, Chongqing Medical University, 1 YiXueYuan Road, Chongqing, Sichuan 400016, P.R. China

E-mail: ahuang@cqum.edu.cn

E-mail: yixin_xinyuan@163.com

Key words: hepatitis B virus, reactivation, chemotherapy, epirubicin, mechanism a novel mechanism of HBV reactivation following cytotoxic anticancer chemotherapy.

\section{Introduction}

Hepatitis B virus (HBV) infection is a serious public health problem worldwide, with $\sim 400$ million chronic HBV surface antigen (HBsAg) carriers (1). In the majority of patients, the virus is quiescent or replicating at low levels. However, chemotherapy may disrupt the balance between the host immune responses and viral replication, and enhanced viral replication is a universal phenomenon in clinical cases (2).

The mechanisms of HBV reactivation are not completely understood. The majority of studies consider there to be at least two mechanisms responsible for this phenomenon. One is the suppression and reconstitution of the host immune response following chemotherapy, which is pivotal in controlling HBV infection and replication (1). Another is the direct stimulatory effect anticancer agents, including glucocorticoids, may have on viral replication. Corticosteroids increase HBV expression in vitro by binding to the glucocorticoid-responsive element and augmenting the HBV enhancer I $(3,4)$. However, steroid-free chemotherapy may also promote viral replication (5). In certain cases, HBV reactivation occurred within the first two weeks of chemotherapy (6), which was likely to be prior to immune reconstitution following withdrawal of the anticancer agents. One possible mechanism for the early reactivation of $\mathrm{HBV}$ is that cytotoxic agents may have a direct stimulatory effect on HBV replication.

In the present study, the aim was to investigate whether epirubicin stimulates HBV replication directly. If this hypothesis is valid, it may be a novel mechanism of the HBV reactivation caused by cytotoxic chemotherapy.

\section{Materials and methods}

Construction of the stable $H B V$-expressing cell line, HepG2-HBV1.1. HepG2 cells (American Type Culture 
Collection, Rockefeller, MD, USA) were transfected with pneo-CH9/HBV1.1 (Center for Molecular Biology, Heidelberg University, Heidelberg, Germany; recipient, Dr Lanlin, Southwest Hospital affiliated to Third Military Medical University, Chongqing, China) (7), which contains the cytomegalovirus promoter and 1.1 copies of the HBV genome, and then selected with G418 antibiotic $(1,200 \mu \mathrm{g} / \mathrm{ml}$; Merck and Co., Inc., Rahway, NJ, USA). Isolated cell colonies with the HBV genome integrated were selected subsequent to confirmation by Southern blotting and western blot analysis.

Cell culture and treatment. HepG2, HepG2-HBV1.1 and HepG2.2.15 (Xiangya School of Medicine, Central South University, Changsha, China) cells were cultured in minimum essential medium (MEM; Gibco-BRL, Grand Island, NY, USA) with $10 \%$ fetal bovine serum (FBS; Hyclone, Shanghai, China) and maintained in a humidified incubator with $5 \% \mathrm{CO}_{2}$ at $37^{\circ} \mathrm{C}$. For cytotoxic chemotherapy treatment, the cells were incubated with epirubicin (0-1 $\mu \mathrm{M}$, Hisun Chemical Co., Ltd., Zhejiang, China) for $24 \mathrm{~h}$. The medium was then replaced with fresh serum-free MEM medium for a further $48 \mathrm{~h}$ incubation and the cells were then harvested.

Effects of epirubicin on the viability of HepG2.2.15 and HepG2-HBV1.1 cells by trypan blue exclusion assay. HepG2.2.15 (4x10 cells/well) and HepG2-HBV1.1 $\left(6 \times 10^{5}\right.$ cells/well) cells were seeded in six-well plates. Following adherence of the cells, epirubicin was added to the medium at various concentrations $(0-1 \mu \mathrm{M})$ for $24 \mathrm{~h}$, followed by $48 \mathrm{~h}$ incubation in a drug-free culture medium. The cells in each well were washed with phosphate-buffered saline twice following the addtion of $200 \mu \mathrm{l}$ trypsin, and then placed in a $37^{\circ} \mathrm{C} 5 \% \mathrm{CO}_{2}$ incubator for $1-2 \mathrm{~min}$. Subsequently $800 \mu \mathrm{l} 10 \%$ FBS MEM was added to each well to terminate the reaction, and the cell suspension by pipetting several times to disperse the cells evenly and count the cell number. The viability of cells $=$ live cells $/$ total cells .

MTT assay. HepG2.2.15 (1 $10^{5}$ cells/well) and HepG2-HBV1.1 ( $1 \times 10^{5}$ cells/well) cells were inoculated in 96-well plates. Following adherence of the cells, epirubicin was added to the medium at various concentrations $(0-1 \mu \mathrm{M})$ for $24 \mathrm{~h}$, and then $20 \mu \mathrm{l} 0.5 \%$ MTT solution was added to each well for $4 \mathrm{~h}$. Subsequently, the medium in each well was discarded and $150 \mu \mathrm{l}$ DMSO was added. The plate was agitated for $10 \mathrm{~min}$ in order to dissolve the crystals and the absorbance of each well was measured at an optical denisty of $490 \mathrm{~nm}$.

Quantification of HBV DNA copies by fluorescent quantitative polymerase chain reaction $(q P C R)$. HBV replicative intermediates in the cells were obtained as follows. Cells from one $35-\mathrm{mm}$ diameter dish were lysed with $0.5 \mathrm{ml}$ lysis buffer containing $10 \mathrm{mM}$ Tris- $\mathrm{HCl}$ (pH 8.0), 1 mM EDTA, $1 \%$ NP-40 and $2 \%$ sucrose at $37^{\circ} \mathrm{C}$ for $10 \mathrm{~min}$. The cell debris and nuclei were removed by centrifugation at $13,000 \mathrm{xg}$ and the supernatant was mixed with $200 \mu 135 \%$ polyethylene glycol (PEG) 8000 (Beyotime Institute of Biotechnology, Shanghai, China) containing $1.5 \mathrm{M} \mathrm{NaCl}$. Subsequent to incubation on ice for $2 \mathrm{~h}$, the viral nucleocapsids were pelleted by centrifuga- tion at $12,000 \mathrm{xg}$ for $10 \mathrm{~min}$ at $4^{\circ} \mathrm{C}$, followed by $24 \mathrm{~h}$ digestion at $37^{\circ} \mathrm{C}$ in $400 \mu \mathrm{l}$ digestion buffer containing $0.5 \mathrm{mg} / \mathrm{ml}$ pronase (Takara Bio, Inc., Shiga, Japan), $0.5 \%$ sodium dodecyl sulfate (SDS), $10 \mathrm{mM}$ Tris- $\mathrm{HCl}(\mathrm{pH}$ 8.0) and $10 \mathrm{mM}$ EDTA. The digestion mixture was extracted twice with phenol, and the DNA was precipitated with ethanol and dissolved in Tris-EDTA (10 mM Tris-HCl, pH 8.0, 1 mM EDTA) buffer. In order to collect viral particles instead of free viral DNA in the culture medium, the supernatant was subjected to $35 \%$ PEG 8000 precipitation overnight according to the methods of a previous study (8) and then the precipitates were digested as previously described.

The quantification of HBV copies was performed by SYBR-Green assays using FastStart Universal SYBR-Green Master mix (Roche Diagnostics GmbH, Mannheim, Germany). Primers for amplification of the HBV DNA fragments were designed specifically for the conserved region of the HBV gene by Huada Gene Sci-Tech Company (Shenzhen, China) and the sequences were as follows: Forward primer (F2150), 5'-CCTAGTAGTCAGTTATGTCAAC-3'; and reverse primer (R2300), 5'-TCTATAAGCTGGAGGAGTGCGA-3'. The plasmid pneo-CH9/HBV1.1 at different concentrations $\left(5 \times 10^{2}\right.$, $5 \times 10^{3}, 5 \times 10^{4}, 5 \times 10^{5}, 5 \times 10^{6}$ and $5 \times 10^{7}$ copies $\left./ \mu 1\right)$ served as a template to make the standard curve.

Quantification of $H B V$ pregenomic (pg)RNA by fluorescent $q P C R$. Total RNA was extracted by a DNA-free RNA Mini Extraction kit (Watson, Shanghai, China) and $1 \mu \mathrm{g}$ total RNA was used for cDNA synthesis, which was conducted by reverse transcription using the PrimeScript RT reagent kit (Perfect Real Time; Takara Bio, Inc.). Relative quantification of the target genes (HBV $3.5 \mathrm{~kb}$ mRNA) was performed using SYBR Green assays, with $\beta$-actin mRNA as an endogenous control. The expression values of the target genes were calculated using the $2^{-\Delta \Delta \mathrm{Ct}}$ method.

Southern blot analysis. HBV replicative intermediates were extracted from the cells or the supernatant of the culture medium according to the methods previously described and then separated on $0.8 \%$ agarose gels. The DNA samples were transferred to nylon membranes (Roche Diagnostics $\mathrm{GmbH}$ ). Subsequent to ultraviolet crosslinking and prehybridization, the membranes were hybridized with a digoxigenin-labeled HBV-specific probe using a Random-Primed DNA Labeling kit (Roche Diagnostics $\mathrm{GmbH}$ ). The signal was detected by exposure on an X-ray film and scanning using the Versa Doc Imaging system (Bio-Rad, Hercules, CA, USA).

Enzyme-linked immunosorbent assay (ELISA). The levels of HBsAg and HBV e antigen (HBeAg) in the culture medium and cell extracts were assessed by ELISA using Antibody to Hepatitis B Surface Antigen and Antibody to Hepatitis B Virus E Antigen ELISA kits, according to the manufacturer's instructions (Kehua Biotech Co, Ltd, Shanghai, China). The levels of $\mathrm{HBV}$ core antigen $(\mathrm{HBcAg})$ in the culture medium were assessed using an ELISA kit (Disease Diagnosis Reagent and Vaccine Engineering Technology Research Center of China Infectious State, Xiamen University, Xiamen, China). This kit contained two types of 96-well plate. One was coated with HBsAb, to capture only the Dane particle. The other was 
coated with $\mathrm{HBcAb}$, therefore it detected the total $\mathrm{HBcAg}$ from the Dane particles and the HBV nucleocapsids. Each experiment was performed in triplicate and independently repeated three times.

Western blot analysis of HBcAg expression. Cellular proteins were extracted using radio immunoprecipitation buffer supplemented with phenylmethanesulfonyl fluoride. Protein concentrations were determined using a bicinchoninic acid assay protein concentration determination kit (Beyotime Institute of Biotechnology, Shanghai, China). Equal quantities of sample were separated using 10\% SDS-polyacrylamide gel electrophoresis and transferred to polyvinylidene fluoride membranes. The membranes were incubated with monoclonal mouse anti-HBcAg (6D1D10E4; Huazhong University of Science and Technology, Wuhan, China; diluted 1:150) or monoclonal rabbit anti- $\beta$-actin (Santa Cruz Biotechnology, Inc., Santa Cruz, CA, USA; diluted 1:2,500). Following incubation, the membranes were washed three times, and goat anti-rabbit or goat anti-mouse secondary antibody (Santa Cruz Biotechnology, Inc.; diluted 1:2,500) was added for $1 \mathrm{~h}$. The membranes were washed three times with Tris-buffered saline and Tween 20 buffer, and signals were detected using the Enhanced Chemiluminescence Detection system (Pierce Biotechnology, Inc., Rockford, IL, USA).

Statistical analysis. The data are presented as the mean \pm standard deviation of at least three independent experiments. Statistical significance was determined by Student's t-test. The differences between groups were assessed by one-way analysis of variance using the Bonferroni post hoc test and $\mathrm{P} \leq 0.05$ was considered to indicate a statistically significant difference. All analyses were performed using the Statistical Package for the Social Sciences statistical software for Windows, version 10.1.4 (SPSS, Inc., Chicago, IL, USA).

\section{Results}

Effect of epirubicin on the viability of stable HBV-expressing cell lines. Epirubicin, as a cytotoxic chemotherapy agent, induces cell apoptosis or necrosis at high concentrations $(8,9)$, which may be associated with HBV replication. The aim of the present study was to investigate whether epirubicin promotes HBV replication at lower concentrations. The cytotoxicity of epirubicin on HepG2.2.15 and HepG2-HBV1.1 cells was examined using trypan blue exclusion and MTT assays. From the results of the two assays (Fig. 1), $0.5 \mu \mathrm{M}$ epirubicin was revealed to exhibit no significant cytotoxicity to either HepG2.2.15 or HepG2-HBV1.1 cells. Therefore, in subsequent experiments, $0.5 \mu \mathrm{M}$ served as the working concentration of epirubicin.

$H B V D N A$ and pgRNA levels increase concentration-dependently in stable $H B V$-expressing cell lines following epirubicin treatment. HepG2.2.15 (10) and HepG2-HBV1.1 (11) cells were employed as stable HBV-expressing cell lines. HepG2.2.15 ( $4 \times 10^{5}$ cells/well) and HepG2-HBV1.1 $\left(6 \times 10^{5}\right.$ cells/well) cells were treated with epirubicin at various concentrations $(0-0.5 \mu \mathrm{M})$ for $24 \mathrm{~h}$, followed by $48 \mathrm{~h}$ incubation in drug-free culture medium. Intracellular HBV nucleocapsids were
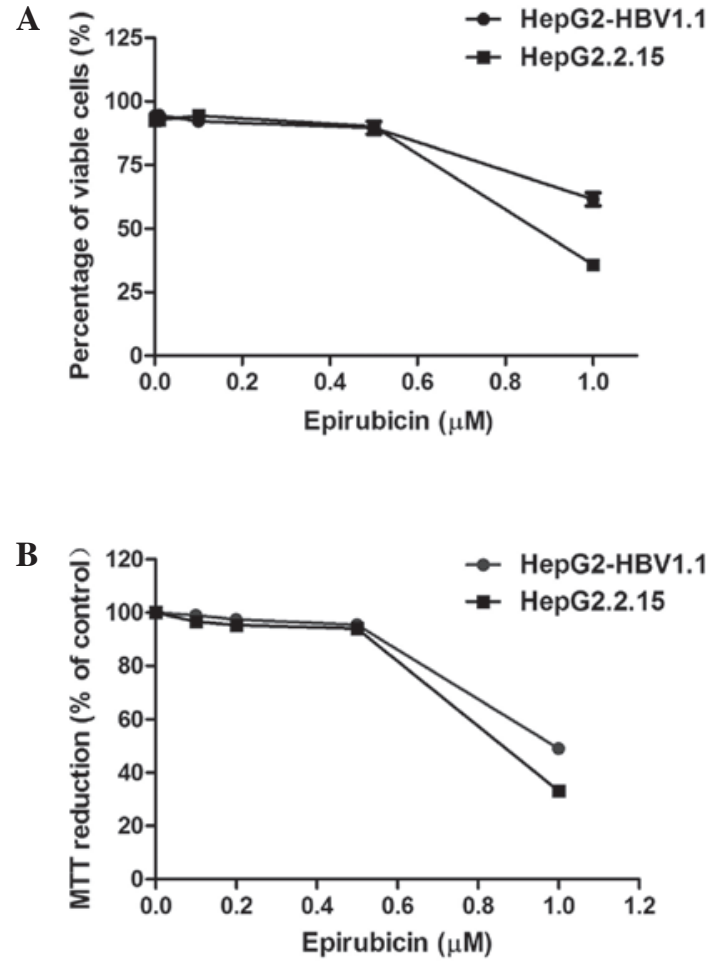

Figure 1. Effects of epirubicin on the viability of stable HBV-expressing cell lines. (A) The effects of epirubicin on the viability of HepG2.2.15 and HepG2-HBV1.1 cells by trypan blue exclusion assay. HepG2.2.15

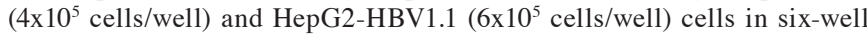
plates were treated with epirubicin at various concentrations $(0-1 \mu \mathrm{M})$ for $24 \mathrm{~h}$, followed by $48 \mathrm{~h}$ incubation in a drug-free culture medium. The cells were collected at $72 \mathrm{~h}$ after the drug treatment. (B) The effects of epirubicin on the viability of HepG2.2.15 and HepG2-HBV1.1 cells by MTT assay. Each well of a 96-well plate was inoculated with $1 \times 10^{5}$ HepG2.2.15 and HepG2-HBV1.1 cells. The cells were treated with epirubicin at various concentrations $(0-1 \mu \mathrm{M})$ for $24 \mathrm{~h}$. Results are expressed as the arithmetic mean \pm standard deviation from three independent experiments. HBV, hepatitis B virus.

extracted at $72 \mathrm{~h}$ after drug treatment, and viral replication intermediates were subsequently measured by fluorescent qPCR and Southern blot analysis. The number of HBV DNA copies was concentration-dependently upregulated upon epirubicin stimulation (Fig. 2A). The number of intracellular HBV DNA copies increased 6.35 \pm 0.49 - and 11.26 \pm 1.31 -fold in the HepG2.2.15 and HepG2-HBV1.1 cells, respectively, with $0.5 \mu \mathrm{M}$ epirubicin treatment. Similarly, the concentration-dependent effect of epirubicin on HBV replication in the cells was confirmed by Southern blot analysis (Fig. 2B). The HBV DNA was extracted from the supernatant of the culture medium following precipitation by PEG 8000 and analyzed using qPCR (Fig. 2C) and Southern blotting (Fig. 2D). Epirubicin upregulated the levels of HBV DNA in the supernatant in a concentration-dependent manner. Additionally, $0.5 \mu \mathrm{M}$ epirubicin increased the secretion of HBV DNA copies by $6.30 \pm 0.57$ - and $6.31 \pm 1.17$-fold in the HepG2.2.15 and HepG2-HBV1.1 cells, respectively. To further determine the effects of epirubicin on the levels of HBV RNA, the levels of $\mathrm{HBV}$ pgRNA were measured by qPCR using primers targeting the $3.5 \mathrm{~kb}$ mRNA of the viral genome. The levels of HBV pgRNA increased markedly with epirubicin treatment (Fig. 3). 
A

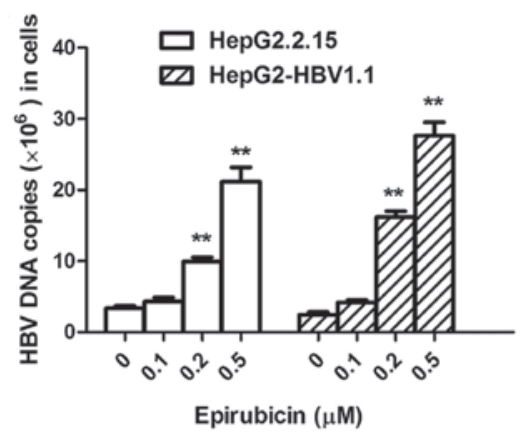

C

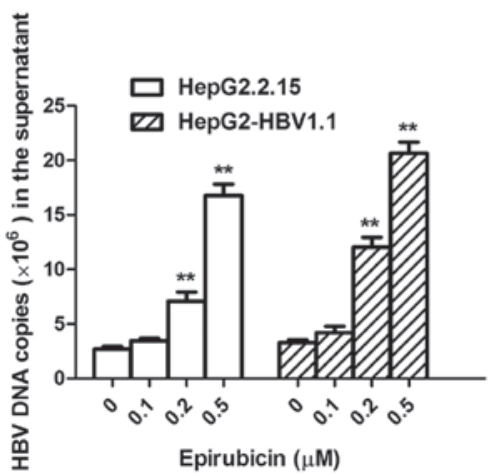

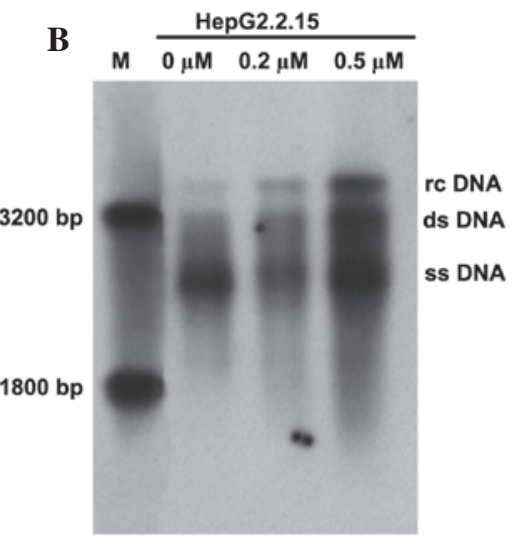

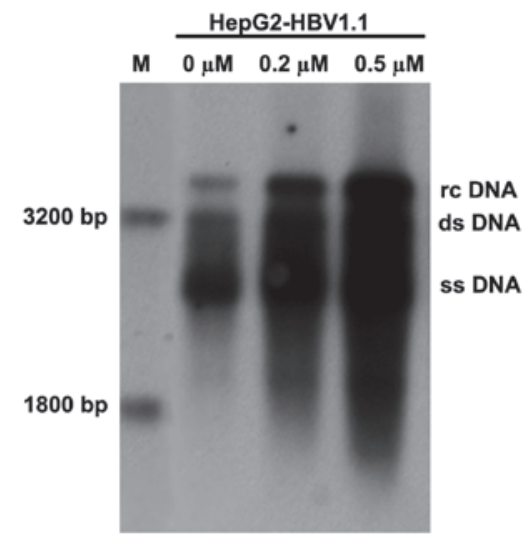

Figure 2. Concentration-dependent increase in the levels of HBV DNA in stable HBV-expressing cell lines treated with epirubicin. (A) A concentration-dependent increase in the levels of HBV DNA in HepG2-HBV1.1 and HepG2.2.15 cells was detected in those treated with epirubicin by qPCR analysis. (B) A concentration-dependent increase in the levels of HBV DNA was detected in HepG2-HBV1.1 and HepG2.2.15 cells treated with epirubicin by Southern blot analysis. (C) The levels of HBV DNA in the supernatant of HepG2-HBV1.1 and HepG2.2.15 cells were increased in a concentration-dependent manner by epirubicin, as detected by qPCR analysis. (D) The levels of HBV DNA in the supernatant of HepG2-HBV1.1 and HepG2.2.15 cells were increased by $0.5 \mu \mathrm{M}$ epirubicin, as detected by Southern blot analysis. Values present the mean \pm standard deviation of three independent experiments." $\mathrm{P}<0.01$, vs. untreated. HBV, hepatitis B virus; qPCR, quantitative polymerase chain reaction; bp, base pairs; rc DNA, relaxed circular DNA; ds DNA, double-stranded DNA; ss DNA, single-stranded DNA.

Epirubicin promotes $H B V$ protein expression. To elucidate the effects of epirubicin on the HBV proteins expressed, the levels of $\mathrm{HBeAg}, \mathrm{HBcAg}$ and $\mathrm{HBsAg}$ were detected by ELISA and western blot analysis. With $0.5 \mu \mathrm{M}$ epirubicin treatment, the levels of HBeAg in the supernatant were upregulated, as detected by ELISA (Fig. 4A), and the levels of HBcAg expression in the cytoplasm increased markedly, as detected by western blot analysis (Fig. 4B). Notably, epirubicin increased the levels of HBsAg expression in the cytoplasm (Fig. 4C), while the levels of HBsAg secretion were not markedly increased (Fig. 4D).

Epirubicin promotes the excretion of $H B V$ nucleocapsids in stable $H B V$-expressing cells. To investigate why the levels of HBsAg secretion did not increase with epirubicin treatment, the $\mathrm{HBcAg}$ levels in the supernatant were detected by ELISA. As the HBV virus cannot secrete free $\mathrm{HBcAg}$ into the culture medium, $\mathrm{HBcAg}$ in the supernatant can only be from HBV Dane particles or HBV nucleocapsids. Therefore, the HBcAg in the supernatant represents the levels of HBV Dane particles or nucleocapsids. However, no significant change in the levels of Dane particles in the supernatant was identified

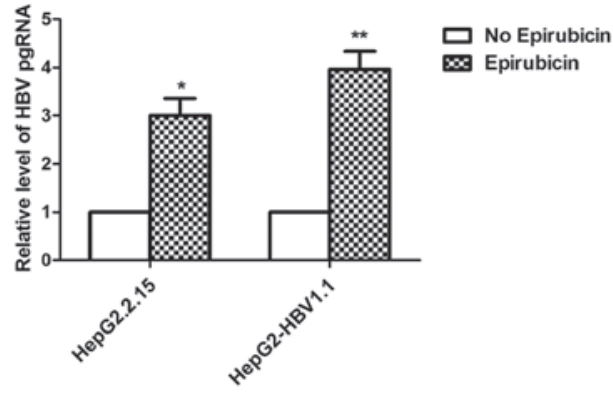

Figure 3. Levels of HBV RNA in the stable HBV-expressing cell lines were increased by treatment with epirubicin, which upregulated the levels of HBV pgRNA, as detected by fluorescent qPCR analysis. HepG2-HBV1.1 $\left(6 \times 10^{5}\right.$ cells/well $)$ and HepG2.2.15 $\left(4 \times 10^{5}\right.$ cells/well) cells were treated with $0.5 \mu \mathrm{M}$ epirubicin for $24 \mathrm{~h}$, followed by $48 \mathrm{~h}$ incubation in drug-free culture medium. Total RNA was extracted at $72 \mathrm{~h}$ after the drug treatment. Values are the mean \pm standard deviation of three independent experiments. ${ }^{*} \mathrm{P}<0.05$, ${ }^{* *} \mathrm{P}<0.01$, vs. untreated. HBV, hepatitis B virus; pgRNA, pregenomic RNA; $\mathrm{qPCR}$, quantitative polymerase chain reaction.

following treatment with epirubicin, although the overall levels of $\mathrm{HBcAg}$ from Dane particles and nucleocapsids in the supernatant markedly increased following $0.5 \mu \mathrm{M}$ epirubicin 
A

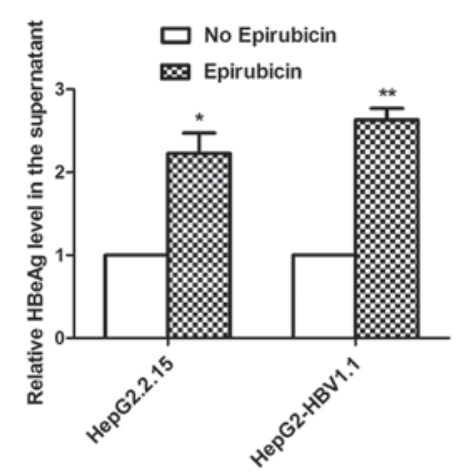

C

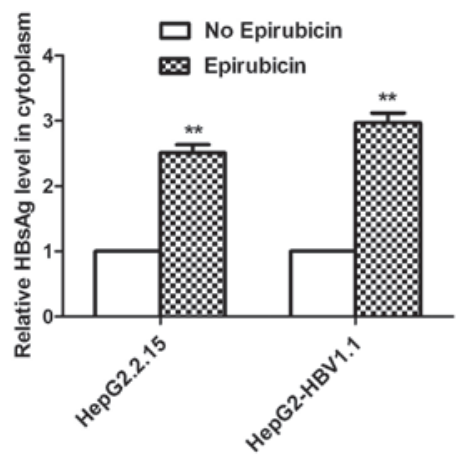

B

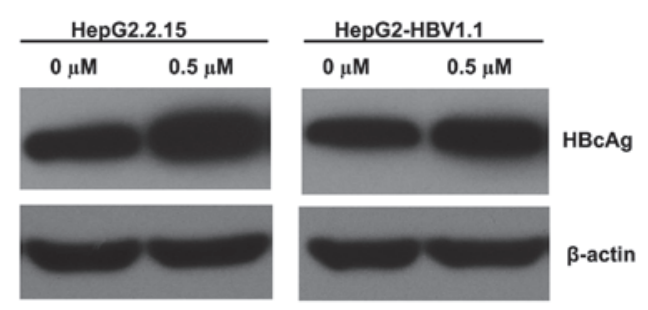

D

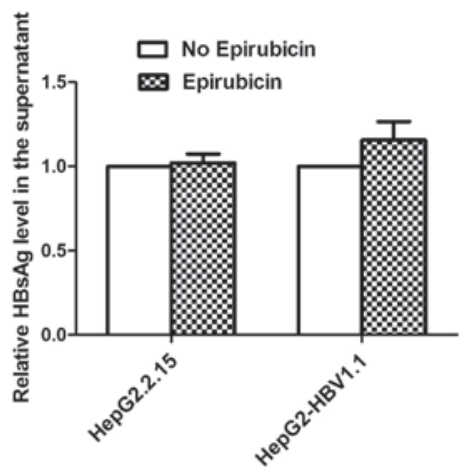

Figure 4. Epirubicin promoted HBV protein expression in HepG2-HBV1.1 and HepG2.2.15 cells. (A) Epirubicin upregulated the levels of HBeAg expression. The levels of HBeAg in the supernatant were analyzed by ELISA. (B) Epirubicin increased the levels of cellular HBcAg expression, as detected by western blot analysis. (C) The effect of epirubicin on the levels of intracellular HBsAg expression was analyzed by ELISA. (D) The effect of epirubicin on the levels of HBsAg expression in the supernatant was analyzed by ELISA. HepG2-HBV1.1 (6x10 ${ }^{5}$ cells/well) and HepG2.2.15 (4x10 5 cells/well) cells were treated with $0.5 \mu \mathrm{M}$ epirubicin for $24 \mathrm{~h}$, followed by $48 \mathrm{~h}$ incubation in drug-free culture medium. Values present the mean \pm standard deviation of three independent experiments. ${ }^{*} \mathrm{P}<0.05,{ }^{* *} \mathrm{P}<0.01$ vs. untreated. HBV, hepatitis B virus; HBeAg, HBV e antigen; HBcAg, HBV core antigen; HBsAg, HBV surface antigen; ELISA, enzyme-linked immunosorbent assay.

treatment (Fig. 5). This result suggests that epirubicin induced HepG2-HBV1.1 cells to excrete HBV nucleocapsids instead of HBV Dane particles.

\section{Discussion}

HBV reactivation is an emerging clinical challenge in $\mathrm{HBV}$ carriers receiving anticancer chemotherapy. All types of anticancer drugs used in chemotherapy have been associated with HBV reactivation, including the classic cytostatics, monoclonal antibodies and steroids (12). The rate of HBV reactivation is highest in patients with breast cancer (41-56\%; $2,13)$ and lymphoma $(24-67 \% ; 14,15)$. This high incidence may be explained in part by the intensive chemotherapy required to treat the diseases.

Epirubicin is one of the most commonly used drugs to treat breast cancer and lymphoma, particularly in patients who have undergone surgery to remove the tumor. Similar to other cytotoxic drugs, epirubicin exhibits immunosuppressive activity, which is considered to be the main mechanism of HBV reactivation. However, there may be other mechanisms responsible for the HBV reactivation caused by cytotoxic anticancer drugs in addition to immunosuppression.

In the present study, the effects of epirubicin on HBV replication in HepG2.2.15 and HepG2-HBV1.1 cells were observed. The number of HBV DNA copies was concentration-dependently increased by epirubicin in the cytoplasm and

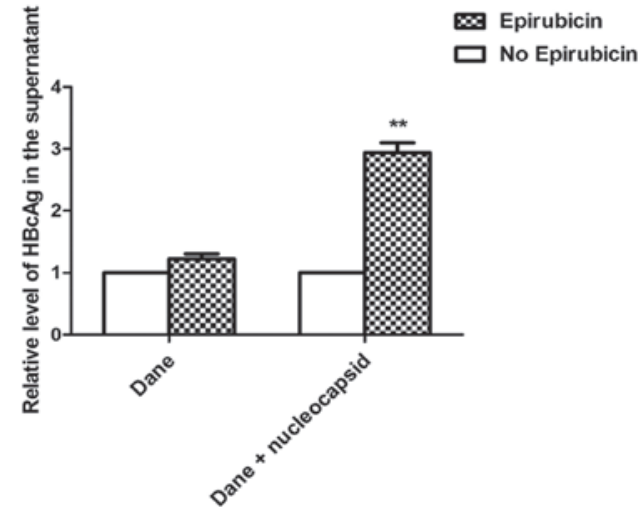

Figure 5. Epirubicin promoted HepG2-HBV1.1 cells to excrete HBV nucleocapsids instead of HBV Dane particles. HepG2-HBV1.1 cells $\left(6 \times 10^{5}\right.$ cells/well) were treated with epirubicin at a concentration of $0.5 \mu \mathrm{M}$ for $24 \mathrm{~h}$, followed by $48 \mathrm{~h}$ incubation in drug-free culture medium. The levels of HBcAg from HBV Dane particles or nucleocapsids in the supernatant were analyzed by ELISA. Dane, HBcAg from HBV Dane particles; Dane + nucleocapsid, HBcAg from HBV Dane particles and nucleocapsids. Values present the mean \pm standard deviation of three independent experiments. " $\mathrm{P}<0.05,{ }^{* *} \mathrm{P}<0.01$ vs. untreated. HBV, hepatitis B virus; HBcAg, HBV core antigen; ELISA, enzyme-linked immunosorbent assay.

the supernatant of the culture medium. Furthermore, the levels of intracellular HBsAg and $\mathrm{HBcAg}$, and secreted $\mathrm{HBeAg}$ also increased following epirubicin treatment. However, epirubicin did not markedly affect the levels of HBsAg secretion. This 
result signified that the abundant secretion of HBV DNA copies stimulated by epirubicin was not extracted from HBV Dane particles, as HBsAg is the main component of the outer layer of the particles. By detection of the levels of HBcAg in the supernatant of the cell culture, it was demonstrated that epirubicin promoted the cells to excrete HBV nucleocapsids instead of Dane particles. This corresponds with the lack of significant change in the levels of HBsAg secretion following epirubicin treatment. These results indicate that epirubicin increased the levels of HBV DNA and RNA production, and protein expression but did not affect the levels of secreted virus particles. Similar to this phenomenon, corticosteroids have been demonstrated to increase the total intracellular levels of HBV DNA, RNA and HBsAg without affecting the levels of secreted HBsAg in previous studies $(16,17)$.

HBV nucleocapsids are closely associated with HBV pathogenesis. The outer layer of HBV nucleocapsids consists of $\mathrm{HBcAg}$, which is the main factor responsible for $\mathrm{HBV}$-associated acute liver failure (ALF). Studies have suggested that $\mathrm{HBcAg}$ is able to directly activate $\mathrm{B}$ cells to produce specific antibodies (IgG1 and IgM anti-HBc), without the aid of $\mathrm{T}$ lymphocytes. This implicates the importance of B cell immunity in the pathogenesis of HBV-associated ALF $(18,19)$. In the present study, epirubicin stimulated stable HBV-expressing cells to excrete HBV nucleocapsids, which may be the principle cause of the severe liver damage induced by cytotoxic anticancer drugs.

It has been confirmed that the recovering immune system following withdrawal of cytotoxic drugs plays a role in liver damage. However, the mechanisms for the marked increase in the levels of HBV replication in the early stages of anticancer treatment remain unclear. In the current study, epirubicin increased the levels of HBV DNA, RNA and protein expression, and directly promoted HBV nucleocapsid secretion under cytotoxic stress. This may be a novel mechanism of HBV reactivation in HBV carriers receiving anticancer chemotherapy. One possible link between cytotoxic stresses and activation of $\mathrm{HBV}$ replication is that cell cycle arrest may be induced by cytotoxic drugs (20-22). The present study also demonstrated that the cell cycle was inhibited at the G2/M-phase by epirubicin (data not shown). Further studies are required to confirm these hypotheses.

\section{Acknowledgements}

This study was supported by the National Natural Science Foundation of China (grant nos. 81201282 and 30901280), Chongqing Natural Science Foundation (grant no. cstc2012jjA10047) and the Ph.D. Programs Foundation of Ministry of Education of China (grant no. 20125503120004).

\section{References}

1. Liu CJ, Chen PJ, Chen DS and Kao JH: Hepatitis B virus reactivation in patients receiving cancer chemotherapy: natural history, pathogenesis, and management. Hepatol Int 7: 316-326, 2013.

2. Lubel JS and Angus PW: Hepatitis B reactivation in patients receiving cytotoxic chemotherapy: diagnosis and management. J Gastroenterol Hepatol 25: 864-871, 2010.

3. Tur-Kaspa R, Burk RD, Shaul Y and Shafritz DA: Hepatitis B virus DNA contains a glucocorticoid-responsive element. Proc Natl Acad Sci USA 83: 1627-1631, 1986.
4. Liaw YF: Hepatitis viruses under immunosuppressive agents. J Gastroenterol Hepatol 13: 14-20, 1998.

5. Cheng AL, Hsiung CA, Su IJ, Chen PJ, Chang MC, Tsao CJ, Kao WY, Uen WC, Hsu CH, Tien HF, et al; Lymphoma Committee of Taiwan Cooperative Oncology Group: Steroid-free chemotherapy decreases risk of hepatitis B virus (HBV) reactivation in HBV-carriers with lymphoma. Hepatology 37: 1320-1328, 2003.

6. Hwang JP, Vierling JM, Zelenetz AD, Lackey SC and Loomba R: Hepatitis B virus management to prevent reactivation after chemotherapy: a review. Support Care Cancer 20: 2999-3008, 2012.

7. Nassal M: The arginine-rich domain of the hepatitis B virus core protein is required for pregenome encapsidation and productive viral positive-strand DNA synthesis but not for virus assembly. J Virol 66: 4107-4116, 1992.

8. Muscarella DE and Bloom SE: The contribution of c-Jun $\mathrm{N}$-terminal kinase activation and subsequent Bcl-2 phosphorylation to apoptosis induction in human B-cells is dependent on the mode of action of specific stresses. Toxicol Appl Pharmacol 228: 93-104, 2008.

9. Zhu X, Fu A and Luo KQ: A high-throughput fluorescence resonance energy transfer (FRET)-based endothelial cell apoptosis assay and its application for screening vascular disrupting agents. Biochem Biophys Res Commun 418: 641-646, 2012 .

10. Sells MA, Chen ML and Acs G: Production of hepatitis B virus particles in Hep G2 cells transfected with cloned hepatitis B virus DNA. Proc Natl Acad Sci USA 84: 1005-1009, 1987.

11. Zhang Z, Liu X, Chen J, Su H, Luo Q, Ye J, Tang N, Zhang W, Chen W, Ko BC and Huang A: Heparin sulphate D-glucosaminyl 3-O-sulfotransferase 3B1 plays a role in HBV replication. Virology 406: 280-285, 2010.

12. Manzano-Alonso ML and Castellano-Tortajada G: Reactivation of hepatitis B virus infection after cytotoxic chemotherapy or immunosuppressive therapy. World J Gastroenterol 17: 1531-1537, 2011.

13. Dai MS, Wu PF, Shyu RY, Lu JJ and Chao TY: Hepatitis B virus reactivation in breast cancer patients undergoing cytotoxic chemotherapy and the role of preemptive lamivudine administration. Liver Int 24: 540-546, 2004.

14. Yeo W, Zee B, Zhong S, Chan PK, Wong WL, Ho WM, Lam KC and Johnson PJ: Comprehensive analysis of risk factors associating with Hepatitis B virus (HBV) reactivation in cancer patients undergoing cytotoxic chemotherapy. Br J Cancer 90: 1306-1311, 2004.

15. Yeo W, Chan PK, Zhong S, Ho WM, Steinberg JL, Tam JS, Hui P, Leung NW, Zee B and Johnson PJ: Frequency of hepatitis B virus reactivation in cancer patients undergoing cytotoxic chemotherapy: a prospective study of 626 patients with identification of risk factors. J Med Virol 62: 299-307, 2000.

16. Lau JY, Bain VG, Smith HM, Alexander GJ and Williams R: Modulation of hepatitis B viral antigen expression by immunosuppressive drugs in primary hepatocyte culture. Transplantation 53 . 894-898, 1992.

17. McMillan JS, Shaw T, Angus PW and Locarnini SA: Effect of immunosuppressive and antiviral agents on hepatitis B virus replication in vitro. Hepatology 22: 36-43, 1995.

18. Farci P, Diaz G, Chen Z, Govindarajan S, Tice A, Agulto L, Pittaluga S, Boon D, Yu C, Engle RE, et al: B cell gene signature with massive intrahepatic production of antibodies to hepatitis $\mathrm{B}$ core antigen in hepatitis B virus-associated acute liver failure. Proc Natl Acad Sci USA 107: 8766-8771, 2010.

19. Wu W, Chen Z, Cheng N, Watts NR, Stahl SJ, Farci P, Purcell RH, Wingfield PT and Steven AC: Specificity of an anti-capsid antibody associated with Hepatitis B Virus-related acute liver failure. J Struct Biol 181: 53-60, 2013.

20. Casavant NC, Luo MH, Rosenke K, Winegardner T, Zurawska A and Fortunato EA: Potential role for p53 in the permissive life cycle of human cytomegalovirus. J Virol 80: 8390-8401, 2006.

21. Huang YQ, Wang LW, Yan SN and Gong ZJ: Effects of cell cycle on telomerase activity and on hepatitis B virus replication in HepG2 2.2.15 cells. Hepatobiliary Pancreat Dis Int 3: 543-547, 2004.

22. Wang S, Qiu L, Yan X, Jin W, Wang Y, Chen L, Wu E, Ye X, Gao GF, Wang F, et al: Loss of microRNA 122 expression in patients with hepatitis B enhances hepatitis B virus replication through cyclin G(1) -modulated P53 activity. Hepatology 55: 730-741, 2012. 